\title{
Haemophilus influenzae Measurement
}

National Cancer Institute

\section{Source}

National Cancer Institute. Haemophilus influenzae Measurement. NCI Thesaurus. Code C147457.

The determination of the amount of the organism assigned to the Haemophilus influenzae species in a biological sample. 